\title{
The Incidence and Alliance of Metabolic Syndrome with Cardiovascular Risk Markers among Kodavas
}

\author{
Deepti A. Lokanath ${ }^{1,2}$, Sharada A. Chandrashekariah11, D. Xaviour ${ }^{2}$, Jayashankar Rao² \\ ${ }^{1}$ Department of Biochemistry, Yuvaraja's College, Mysore, India \\ ${ }^{2}$ Anthropological Survey of India, Southern Regional Centre, Bogadi North, Mysore, India \\ Email: deeptilokanath@gmail.com
}

Received 23 May 2014; revised 10 June 2014; accepted 17 June 2014

Copyright (C) 2014 by authors and Scientific Research Publishing Inc. This work is licensed under the Creative Commons Attribution International License (CC BY). http://creativecommons.org/licenses/by/4.0/ (c) (i)

\section{Abstract}

Background: Metabolic syndrome is the major cause for life threatening disorders such as cardiovascular diseases and type 2 diabetes. These disorders are associated with hyperuricemia and the number is growing among the urban population. Methods: A cross sectional study was done among Kodava population by conducting health camps in Mysore district. Metabolic syndrome was defined according to Joint Interim Statement criteria. Anthropometry was done and blood pressure readings were noted. Clinical markers like fasting glucose, triglyceride, high density lipoprotein, CVD markers and uric acid levels were analyzed. Results: The prevalence of metabolic syndrome was $60.77 \%$ and the utmost occurrence was in 41 - 60 age groups. Women were more affected than men (31.58\%) and MetS became pronounced with advance of age. Biochemical levels of C-reactive protein, ApolipoproteinB/ApolipoproteinA1 ratio and uric acid were raised $(P<0.05)$ and the severity correlated with the number of components of metabolic syndrome. Conclusions: This study helped in identifying new subjects with metabolic syndrome wherein, abdominal obesity was the most common abnormality followed by elevated fasting glucose. Female subjects and subjects with increased waist circumference along with mid aged people are more susceptible to MetS which amplified their CVD risk factors and hyperuricemic conditions. Life style modifications and therapeutic approach are critical prerequisite. However, there is an urgent need for further health camps for the awareness, and prevention of MetS and its associated risk factors among Kodavas.

\section{Keywords}

ApoB/ApoA1 Ratio, CRP, Metabolic Syndrome, Abdominal Obesity, Homocysteine, Uric Acid 


\section{Introduction}

Metabolic syndrome (MetS) is a compilation of multiple interrelated risk factors such as obesity, dyslipidemia and decreased glucose tolerance which can ultimately cause cardio vascular diseases (CVD) and type 2 diabetes (T2D) [1]. MetS also causes lipid rich plaques and premature coronary artery disease (CAD) and is said to be the major threat to cardiovascular mortality and morbidity [2] [3]. Studies have shown that prevalence of metabolic syndrome is found to be high among urban Indian population [4].

Kodavas are inhabitants of Kodagu district, Karnataka, South India. They belong to agricultural community with martial traditions and among the population excessive intake of pork meat and alcohol is followed habitually [5] [6]. The dietary habits, migration, sedentary life style and urbanization form the contributing factors of metabolic syndrome among Kodavas. Till date there are no studies available about the magnitude of metabolic syndrome in this community and therefore there is an urgent need to assess this health issue amongst Kodavas. In recent time, people have migrated to other places in India and abroad and the present study was conducted on Kodava community living in Mysore City, Karnataka, India. This study investigates the prevalence and manifestations of metabolic syndrome and also checks their association with other cardiovascular risk markers such as C-reactive protein (CRP), ApolipoproteinB/ApolipoproteinA1 (ApoB/ApoA1 ratio), homocysteine and uric acid.

\section{Methods}

\subsection{Study Design}

This cross sectional study was carried out in Mysore city from June 2011 to January 2012, by conducting 10 health camps with the aid of community concentrated localities and their associations. In this study, 426 subjects aged between 25 and 85 participated but 8 subjects were excluded as they were non-Kodavas or women married to Kodava men. A total of 418 subjects were selected after fulfilling the inclusion criteria in the present study. The subjects were asked to fill-in personal details like name, age, marital status, spouse name, family name which are very essential when we are studying in this community. A standardized questionnaire related to their medical history, medications/treatment, diet, alcohol consumption, smoking status and physical activity were noted. All the subjects gave their written informed consent for participating in the study and this was approved by Institutional Ethical Committee (IOE) Anthropological Survey of India, Kolkata.

\subsection{Anthropometric Measurements}

Anthropometric measurements like height, weight, waist and hip circumference were measured. Height was measured using Holtain anthropometric scale and weight with light clothing and without shoes. Waist circumference was measured using a flexible inextensible tape placed horizontally at the midpoint between the lowest rib and the iliac crest and hip circumference (HC) at the widest circumference over the major trochanters with the subject standing erect and waist hip ratio (WHR) was calculated using these measurements. Body fat \%, Body Mass Index (BMI), Basal Metabolic Rate (BMR) was measured using Omron fat monitor with the subject standing erect without shoes. Blood pressure was measured using mercury Sphygmomanometer in sitting position.

\subsection{Sample Collection and Laboratory Analysis}

After overnight fast, $10 \mathrm{ml}$ of venous blood was collected in EDTA vacutainer, plasma was separated and tested for fasting plasma glucose, High Density lipoprotein-cholesterol (HDL-C), Triglyceride (TG), C-Reactive Protein (CRP) using ERBA kits, supplied by Transasia. Uric acid was measured by uricase PAP method using ERBA kits. ApolipoproteinA1 (ApoA1) and ApolipoproteinB (ApoB) were tested using Randox Kits by turbidometric immunoassay method in automated biochemical analyzer EM360 (Transasia, ERBA Mannheim, Germany). Homocysteine was estimated using Immulite kit in Immulite1000 by chemiluminescence technology.

MetS was defined as per Joint Interim Statement (JIS) of the International Diabetes Federation Task Force on Epidemiology and Prevention; National Heart, Lung, and Blood Institute; American Heart Association; World Heart Federation; International Atherosclerosis Society; International Association for the Study of Obesity and also Consensus Statement for Diagnosis of Obesity, Abdominal Obesity and the MetS for Asian Indians [7] [8]. 
The criteria includes increased waist circumference (males $\geq 90 \mathrm{~cm}$ and females $\geq 80 \mathrm{~cm}$ ), Hypertriglyceridemia (TG $\geq 150 \mathrm{mg} / \mathrm{dl}$ ), low HDL (males $<40 \mathrm{mg} / \mathrm{dl}$ and females $<50 \mathrm{mg} / \mathrm{dl}$ ), elevated blood pressure (systolic blood pressure $\geq 130 \mathrm{mmHg}$ and/or diastolic blood pressure $\geq 85 \mathrm{mmHg}$ or under drug treatment for hypertension) and elevated blood sugar (fasting blood sugar $\geq 100 \mathrm{mg} / \mathrm{dl}$ or under treatment for diabetes mellitus). Thus, any three of the above mentioned parameters will confirm the presence of MetS.

We referred the kit ranges for the cut off values of CRP ( $>1 \mathrm{mg} / \mathrm{dl})$, ApoA1/ApoB ratio ( $>0.8 \mathrm{mg} / \mathrm{dl})$, homocysteine (>15 $\mu \mathrm{mol} / \mathrm{l})$ and uric acid ( $>7.7 \mathrm{mg} / \mathrm{dl}$ men and $>6.6 \mathrm{mg} / \mathrm{dl}$ women).

\subsection{Statistical Analysis}

For determining the sample size, creative research system survey software was used with confidence level of 95\% and confidence interval of 4.74. With a population of 15,000 in Mysore district wherein the overall population of the community is 125,000 according to Karnataka unit of Bureau of economics and statistics (2011).

All statistical analysis was performed using SPSS version 12.0 software (SPSS, Chicago, IL, USA). Continuous data were presented as mean and categorical data expressed as numbers and percentages. Differences between continuous data were analyzed by independent student's t-test and categorical data by chi square test. Comparisons between the groups based on MetS components were done by Analysis of variance for continuous data.

\section{Results}

In this study, out of 418 subjects, 254 (60.77\%) had MetS, there were significant differences in the anthropometric measurements like BMI, Body fat \% and WHR among subjects with metabolic syndrome and normal subjects. There were noteworthy difference in blood pressure readings but not in alcohol intake and physical activity in Mets and non-Mets group (Table 1). Figure 1 shows the prevalence of MetS based on gender, women (31.58\%) were more affected than men (29.19\%). Figure 2 describes the manifestations of metabolic syndrome, Increased waist circumference (54.54\%) and impaired glucose tolerance (50\%) were the most common problem in MetS subjects. More over in women (22.73\%) low HDL was highly prevalent than men. The prevalence of metabolic syndrome by age was explained in Figure 3. In the 41 - 60 age group both men and women displayed highest incidence. However with increase in age ( $>60$ yrs) more women were affected than men. Table 2 shows significant differences in levels of CRP, ApoB/ApoA1 ratio and uric acid $(\mathrm{P}<0.05)$ in MetS and normal subjects. Further there is a steady increase in the levels of CRP, ApoB/ApoA1 ratio and uric acid as the components

\section{Table 1. Baseline characteristics of subjects with and without metabolic syndrome.}

\begin{tabular}{|c|c|c|c|}
\hline Variables & Metabolic syndrome (254) & Normal subjects (164) & $P$ value \\
\hline Males & 122 & 72 & 0.409 \\
\hline Females & 132 & 92 & 0.000 \\
\hline Age & 55.28 & 50.89 & 0.012 \\
\hline Type 2 diabetes & 77 & 16 & 0.000 \\
\hline Cariovascular disease & 6 & 3 & 0.000 \\
\hline Body Mass Index & $27.10 \pm 3.42$ & $24.50 \pm 3.45$ & 0.000 \\
\hline Waist hip ratio & $0.92 \pm 0.090$ & $0.871 \pm 0.077$ & 0.000 \\
\hline Body fat $\%$ & $33.56 \pm 6.45$ & $31.13 \pm 6.28$ & 0.000 \\
\hline SBP & $138.85 \pm 18.92$ & $125.95 \pm 19.19$ & 0.000 \\
\hline DBP & $87.24 \pm 10$ & $80.37 \pm 9$ & 0.000 \\
\hline Alcohol intake & 129 & 72 & 0.169 \\
\hline Smoking & 23 & 16 & 0.810 \\
\hline Physical activity & 175 & 110 & 0.794 \\
\hline
\end{tabular}


$60.7 \%$

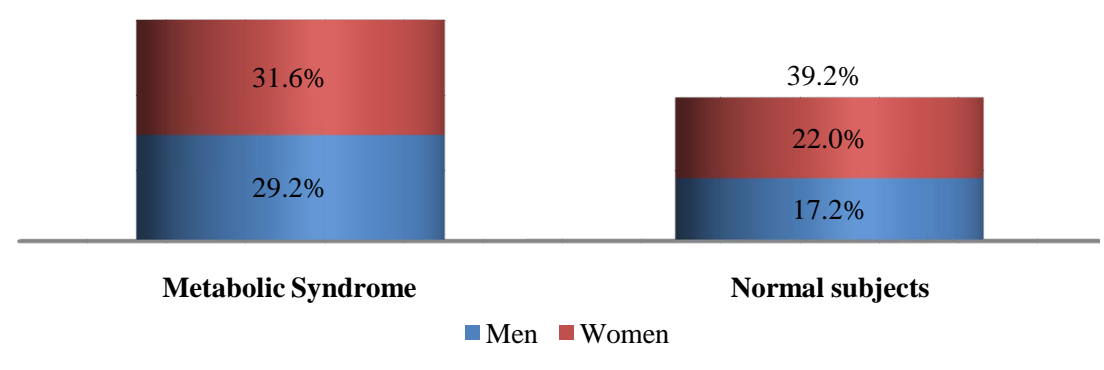

Figure 1. Prevelance of metabolic syndrome amongst men and women.

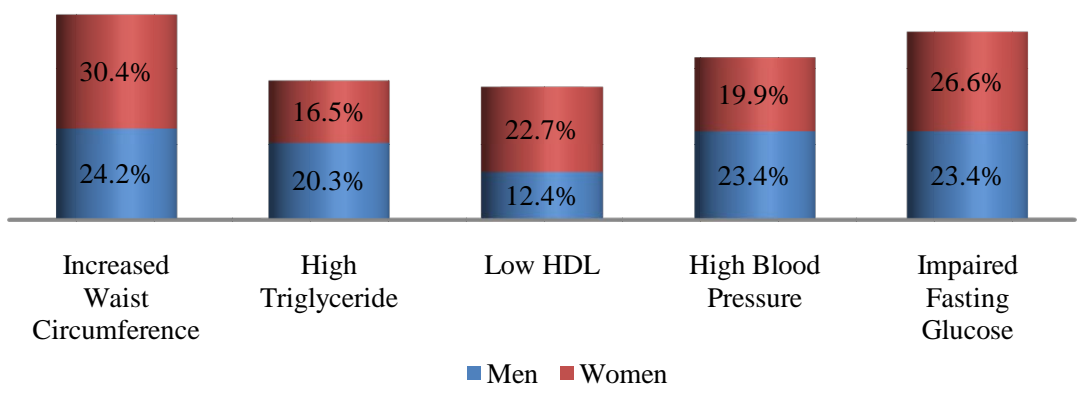

Figure 2. Characterization of metabolic syndrome amongst men and women. $\mathrm{P}$ value by chi square test respectively: $0.00^{*}, 0.05^{*}, 0.00^{*}, 0.02^{*}, 0.433$.

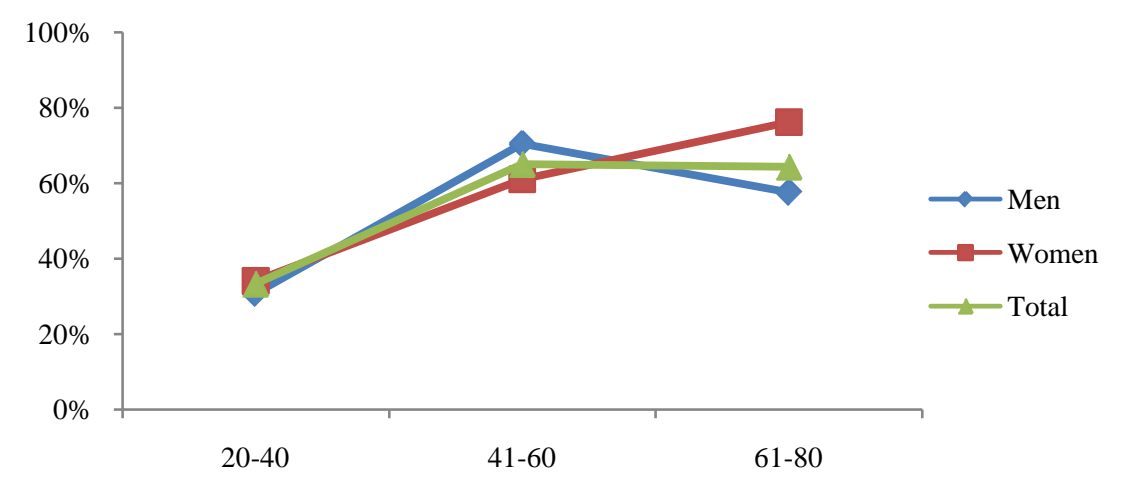

Figure 3. Age wise distribution of metabolic syndrome.

Table 2. Mean of CVD risk markers and uric acid level amongst metabolic syndrome and normal subjects.

\begin{tabular}{cccc}
\hline CVD Markers & Subjects with MetS & Normal subjects & P value \\
\hline CRP mg/dl & 1.823 & 1.789 & $0.017^{*}$ \\
ApoB/ApoA1 ratio mg/dl & 0.772 & 0.627 & $0.034^{*}$ \\
Homocysteine $\mu \mathrm{mol} / \mathrm{L}$ & 16.51 & 16.21 & 0.431 \\
Uric acid $\mathrm{mg} / \mathrm{dl}$ & 6.105 & 5.238 & $0.05^{*}$ \\
\hline
\end{tabular}

of MetS increased and their difference is significant, components refers to metabolic syndrome complications either high waist circumference, high triglyceride, low HDL, Hypertension or Elevated fasting glucose (Table 3). In a similar manner, there is rise in the levels of all CVD risk markers and uric acid in MetS patients of 41 - 60 age groups which is of great concern, except for homocysteine which is found to be high in >60 age group (Figure 4). 


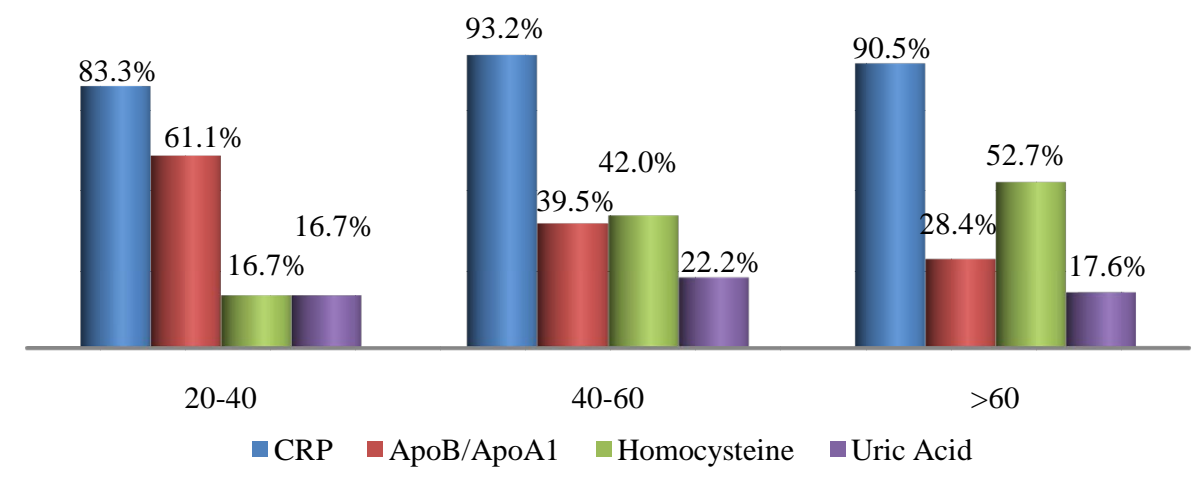

Figure 4. Age-wise distribution of CVD markers and uric acid levels in metabolic syndrome subjects.

Table 3. Metabolic components and their effect on mean of CVD risk markers and uric acid levels.

\begin{tabular}{ccccc}
\hline Number of components & 3 & 4 & 5 & P value \\
\hline CRP mg/dl & 1.700 & 1.93 & 1.99 & $0.005^{*}$ \\
ApoB/ApoA1 ratio mg/dl & 0.65 & 0.733 & 0.777 & $0.003^{*}$ \\
Homocysteine $\mu \mathrm{mol} / \mathrm{L}$ & 16.48 & 14.06 & 16.91 & 0.456 \\
Uric acid mg/dl & 6.01 & 6.09 & 6.488 & $0.000^{*}$ \\
\hline
\end{tabular}

${ }^{*} \mathrm{P}$ value significant; 3-refers to presence of any 3 components of metabolic syndrome; 4-refers to presence of any 4 components of metabolic syndrome; 5 -refers to presence of all components of metabolic syndrome.

\subsection{Ascertainment of CVD}

In this study, 9 subjects reported previous history of cardiovascular problems like Myocardial infarction and had undergone angioplasty, it was known through the questionnaire, of these 7 (77.77\%) were diagnosed with metabolic syndrome.

\subsection{Prevalence of Hyperuricemia/Gout}

In the study, 17 subjects had previous history of hyperuricemia/gout and were on treatment, out of which 13 (76.47\%) were newly diagnosed with metabolic syndrome.

\section{Discussion}

Metabolic syndrome is known to increase the risk of cardiovascular diseases and type 2 diabetes, and its magnitude is reaching pandemic proportions worldwide. Other risk factors like obesity, dyslipidemia, hypertension, insulin resistance and hyperuricemia aggravate the problem. The present study shows the prevalence of metabolic syndrome and their association with non-traditional CVD risk markers and further substantiated with Uric Acid levels.

Studies have shown that one third of the urban population suffer from metabolic syndrome [9]. Urbanization, sedentary life style and globalization of diet have led to high intake of non-traditional fast food which is the leading cause for metabolic syndrome. In our study, overall $60.77 \%$ of the subjects are suffering from metabolic syndrome and this is very high compared to $43.2 \%$ of MetS observed in Urban Eastern population and $41.1 \%$ found in urban Asian Indians [10] [11]. More women (31.58\%) were affected and it was significantly ( $<$ 0.001), higher compared to men (29.19\%) which is similar to study conducted in semi urban area of Baloor (26.5\% men and 31.5\% of women) [12] and community study in Kolkata (48.2\% in women and $16.3 \%$ in men) [13]. Even though the study areas are different in all the above cases more women are affected than men may be due to the changes in occupation, advent of new technologies for domestic use, transition in lifestyle and stress.

Anthropometric indicator-abdominal obesity (54.54\%) is the most persistent problem in the Kodava community and was higher in women, as seen in Chennai study, wherein $49.2 \%$ (38.5\% of men and $58.3 \%$ of women) 
subjects had increased waist circumference [14]. This similarity may be due to lack of physical exercise and excess calorie intake which make them susceptible for metabolic syndrome.

All the biochemical parameters were significantly high in MetS individuals showing dyslipidemia with decreased glucose tolerance according to the guidelines. In the present study, 36.84\% showed hypertriglyceridemia, 35.17\% had low HDL levels, while $43.3 \%$ were with hypertension and 50\% had diabetes. Our result almost corroborates with the South Indian studies which showed high prevalence of metabolic syndrome wherein 31.4\% had abdominal obesity, 45.6\% showed hypertriglyceridemia, 65.5\% had low HDL, 55.4\% were hypertensive and $26.7 \%$ had high fasting plasma glucose [15]. In both the regions the prevalence was high due to exposure to modernization.

Among the study population 209 subjects showed impaired fasting glucose levels out of which $36.84 \%$ were diabetic and were on hypoglycemic drugs and therefore $63.15 \%$ had the risk of acquiring diabetes which is alarming. These results are higher than Mumbai urban population studies wherein total of $40.15 \%$ had history of diabetes and 25\% were at risk of acquiring [16]. Low HDL was more prevalent in female subjects, but it is very much lower compared to rural Indian cross sectional study wherein $65.7 \%$ of women had low HDL [17]. However triglyceride levels were high in male, comparable to western urban subjects. (32.1\% in men and $28.6 \%$ in women) [18] Another risk factor hypertension was observed in 43.3\% study subjects and men were significantly affected however it is lower compared to the study done on rural Wardha region (53.8\%) [19].

Abdominal fat indicated as abdominal obesity (24.16\%) associated with hypertension (23.44\%) was more prevalent in male subjects and is comparable to urban north Indian men of industry study [20]. However in females abdominal obesity was associated with impaired fasting glucose. These results agree with Iranian study wherein WC was the better predictor of metabolic syndrome in women [21].

In our study prevalence of metabolic syndrome is seen in $65 \%$ of 41 - 60 age groups and decreased in men ( $>60)$ which is comparable to the study done on young, and aged nonagenarians [22]. Whereas in female prevalence of MetS increased with age, the gender variations may be due to lack of estrogen in post menopause women. This is very contradicting from the study done on Bangladeshi rural women (39.24\%), but is similar to the German study wherein highest prevalence of metabolic syndrome was seen in 60 - 79 age groups [23] [24].

Studies have shown that metabolic syndrome is the immediate antecedents for cardio vascular diseases [25]. Metabolic syndrome is associated with two fold risk of CVD and subjects with MetS have 30\% - 40\% probability of acquiring CVD within 20 years depending on the components present [26]. Though the components of metabolic syndrome serve as conventional risk factors of CVD, there are several emerging non-traditional CVD markers like CRP, Lp(A), ApoB/ApoA1 ratio and homocysteine which are also associated with metabolic syndrome. This study report on Kodavas is a novel investigation as there is no previous history which associates and evaluates the magnitude of metabolic syndrome with nontraditional CVD risk markers on Indian community.

Uric acid is the new entity which is gaining significance both in developing metabolic diseases as well as CVD [27] [28]. Hyperuricemia is an important marker associated with metabolic syndrome. In the present study mean of uric acid levels in subjects with MetS was $6.105 \mathrm{mg} / \mathrm{dl}$ and non-MetS was $5.238 \mathrm{mg} / \mathrm{dl}$ comparable to study done on obese metabolic Caucasians (MetS $6.6 \mathrm{mg} / \mathrm{dl}$ and non-MetS $6.1 \mathrm{mg} / \mathrm{dl}$ ) [29]. A mild inflammation is associated with metabolic syndrome and it results in potential elevation of inflammatory markers like CRP. The components of the metabolic syndrome showed high correlation with CRP in the study done on American women [30]. The CRP levels in our study showed $1.82 \mathrm{mg} / \mathrm{dl}$ in subjects with metabolic syndrome and in normal subjects it was $1.78 \mathrm{mg} / \mathrm{dl}$ which can be compared with southern California community wherein $3.36 \mathrm{mg} / \mathrm{l}$ and $1.62 \mathrm{mg} / \mathrm{l}$ was observed in patients and normal subjects respectively [31].

Homocysteine has been recently discussed as a strong and independent prognosis factor for CVD [32]. In our study mean level of Homocysteine marginally increased in MetS $(16.51 \mu \mathrm{mol} / \mathrm{L})$ group compared to the NonMetS group $(16.21 \mu \mathrm{mol} / \mathrm{L})$ and was not significant $(\mathrm{P}>0.431)$. Previous report on Mediterranean population showed significant difference among Mets and non-Mets individuals (Met S $12.0 \mu \mathrm{mol} / \mathrm{l}$ and non-MetS 11.9 $\mu \mathrm{mol} / \mathrm{l} \mathrm{P}=0.829)$ [33].

The APO B/APO A1 ratio gives the exact fraction of atherogenic to anti atherogenic lipoprotein ratio which is an upgraded predictor of CVD than LDL and HDL levels. Several clinical studies have shown ApoB/ApoA1 ratio is an accurate risk factor for determining cardio vascular diseases [34], and is related to the components of MetS in the USA population [35]. In our study there is a significant difference in the means of ApoB/ApoA1 ratio (0.772 in MetS and 0.627 in non-MetS P > 0.034) and comparable to the study done on Chinese population 
(0.80 in MetS and 0.54 in non-MetS P > 0.05) [36].

In our study age related distribution of CVD markers in subjects with MetS showed elevated levels of all markers in 41 - 60 age groups, which is intimidating. A high level of homocysteine was observed in 60 age group and above it might be due to lack of intake of diet rich in fruits and vegetables which are sources of vitamin B complex [37]. ApoB/ApoA1 ratio is high (61.11\%) even in young subjects of 20 - 40 age group making them susceptible to CVD.

In our study, we portray a steady increase in the mean of CVD markers as the components of MetS increased comparable to the study done on Chinese geriatric population wherein CVD mortality risk increased with 3, 4 and 5 components of metabolic syndrome [38]. The positive outcome of the study is many Kodava subjects were newly diagnosed with MetS. To obtain more accuracy in our results we have analyzed the cases and controls for CVD markers like CRP, Homocysteine, ApoB/ApoA1 ratio. In contrast most of the studies predict lipid disorders as the only factor for cardiovascular risk rather than testing specific markers to assess CVD. We were not able to diagnose subjects with cardiac disorders, only subjects with previous history were considered, as ECG (Electrocardiography) or angiogram was not feasible in health camps. A follow-up session is required to assess these metabolic syndrome patients after diet, lifestyle and therapeutic modification.

\section{Conclusion}

Thus the study shows prevalence of metabolic syndrome which is high among the Kodava population. Middle aged, female individuals with increased waist circumference and impaired fasting glucose are more liable to metabolic syndrome. Cardiovascular risk markers such as ApoB/ApoA1 ratio, CRP and uric acid levels were high in subjects with metabolic syndrome. Therefore the subjects with metabolic complications have increased risk of hyperuricemia and CVD. The early diagnosis of metabolic syndrome in this population can be used as a precautionary measure to prevent CVD and other co-morbidities which demands strict control over dyslipidemia associated with diabetes. Lifestyle modifications and other therapeutic interventions will have beneficial effects.

\section{Acknowledgements}

The author Deepti A. Lokanath would like to thank Anthropological Survey of India, Kolkata for the financial support. Special thanks to area Associations and Kodava Samaj, Mysore for their support in conducting health camps. All the research scholars and lab technicians of AnSI for their support.

\section{References}

[1] Grundy, S.M. (2006) Metabolic Syndrome. Connecting and Reconciling Cardiovascular and Diabetes Worlds. Journal of American College Cardiology, 47, 1093-1100. http://dx.doi.org/10.1016/j.jacc.2005.11.046

[2] Amano, T., Matsubara, T. and Uetani, T. (2007) Impact of Metabolic Syndrome on Tissue Characteristics of Angiographically Mild to Moderate Coronary Lesions Integrated Backscatter Intravascular Ultrasound Study. Journal of American College Cardiology, 49, 1149-1156. http://dx.doi.org/10.1016/j.jacc.2006.12.028

[3] Iribarren, C., Alan, S.G, Gail, H. and Stephen, S. (2006) Metabolic Syndrome and Early-Onset Coronary Artery Disease: Is the Whole Greater Than Its Parts? Journal of American College Cardiology, 48, 1800-1807. http://dx.doi.org/10.1016/j.jacc.2006.03.070

[4] Misra, A., Misra, R., Wijesuriya, M. and Banerjee, D. (2007) The Metabolic Syndrome in South Asians: Continuing Escalation and Possible Solutions. Indian Journal of Medical Research, 125, 345-354.

[5] Singh, K.S. (2003) Anthropological Survey of India, People of India. Anthropological Survey of India.

[6] Muthanna, I.M. (1971) The Coorg Memoirs (The Story of the Kodavas). Usha Press, Vellore.

[7] Alberti, K.G., Eckel, R.H., Grundy, S.M., Zimmet, P.Z., Cleeman, J.I. and Donato, K.A. (2009) Harmonizing the Metabolic Syndrome. Circulation, 120, 1640-1645. http://dx.doi.org/10.1161/CIRCULATIONAHA.109.192644

[8] Misra, A., Chowbey, P., Makkar, B.M., Vikram, N.K., Wasir, J.S. and Chadha, D. (2009) Consensus Statement for Diagnosis of Obesity, Abdominal Obesity and the Metabolic Syndrome for Asian Indians and Recommendations for Physical Activity, Medical and Surgical Management. Journal of Association Physicians India, 57, 163-170.

[9] Misra, A. and Khurana, L. (2008) Obesity and the Metabolic Syndrome in Developing Countries. Journal of Clinical Endocrinology and Metabolism, 93, S9-S30. http://dx.doi.org/10.1210/jc.2008-1595

[10] Prasad, D.S., Kabir, Z. and Das, B.C. (2012) Prevalence and Risk Factors for Metabolic Syndrome in Asian Indians: A 
Community Study from Urban Eastern India. Journal of Cardiovascular Disease Research, 3, 204-211.

[11] Ramachandran, A., Snehalatha, C., Satyavani, K., Sivasankari, S. and Vijay, V. (2003) Metabolic Syndrome in Urban Asian Indian Adults-A Population Study Using Modified ATP III Criteria. Diabetes Research and Clinical Practice, 60, 199-204. http://dx.doi.org/10.1016/S0168-8227(03)00060-3

[12] Pemminati, S., Prabha Adhikari, M.R., Pathak, R. and Pai, M.R. (2010) Prevalence of Metabolic Syndrome (METS) Using IDF 2005 Guidelines in a Semi Urban South Indian (Baloor Diabetes Study) Population of Mangalore. Journal of Association Physicians of India, 58, 674-677.

[13] Das, M., Pal, S. and Ghosh, A. (2010) Association of Metabolic Syndrome with Obesity Measures, Metabolic Profiles, and Intake of Dietary Fatty Acids in People of Asian Indian Origin. Journal of Cardiovascular Disease Research, 1, 130-135. http://dx.doi.org/10.4103/0975-3583.70911

[14] Deepa, M., Farooq, S., Datta, M., Deepa, R. and Mohan, V. (2007) Prevalence of Metabolic Syndrome Using WHO, ATPIII and IDF Definitions in Asian Indians: The Chennai Urban Rural Epidemiology Study (CURES-34). Diabetes Metabolism Research Review, 23, 127-134. http://dx.doi.org/10.1002/dmrr.658

[15] Kaushik, P., Soumik, G. and Subhankar, C. (2012) Metabolic Syndrome in South Asians. Indian Journal of Endocrinology Metabolism, 16, 44-55.

[16] Sawant, A., Mankeshwar, R., Shah, S., Raghavan, R., Dhongde, G., et al. (2011) Prevalence of Metabolic Syndrome in Urban India. Cholesterol, 2011, Article ID: 920983. http://dx.doi.org/10.1155/2011/920983

[17] Kinra, S., Bowen, L.J., Lyngdoh, T., Prabhakaran, D., Reddy, K.S., Ramakrishnan, L., et al. (2010) Sociodemographic Patterning of Non-Communicable Disease Risk Factors in Rural India: A Cross Sectional Study. British Medical Journal, 341, c4974. http://dx.doi.org/10.1136/bmj.c4974

[18] Gupta, A., Gupta, R., Sarna, M., Rastogi, S., Gupta, V.P. and Kothari, K. (2003) Prevalence of Diabetes, Impaired Fasting Glucose and Insulin Resistance Syndrome in an Urban Indian Population. Diabetes Research and Clinical Practice, 61, 69-76. http://dx.doi.org/10.1016/S0168-8227(03)00085-8

[19] Kamble, P., Deshmukh, P.R. and Garg, N. (2010) Metabolic Syndrome in Adult Population of Rural Wardha, Central India. Indian Journal Medical Research, 132, 701-705.

[20] Prabhakaran, D., Pankaj, S., Vivek, C., Lakshmy, R., Ajay, M. and Srinath, R.K. (2005) Cardiovascular Risk Factor Prevalence among Men in a Large Industry of Northern India. The National Medical Journal of India, 18, 59-65.

[21] Gharipour, M., Sarrafzadegan, N., Sadeghi, M., Andalib, E., Talaie, M., Shafie, D. and Aghababaie, E. (2013) Predictors of Metabolic Syndrome in Iranian Population: Waist Circumference, Body Mass Index or Waist to Hip Ratio? Cholesterol, 2013, Article ID: 198384. http://dx.doi.org/10.1155/2013/198384

[22] Frisard, M.I., Rood, J.C., Fang, X., Su, J., Welsh, D.A., Jazwinski, S.M. and Ravussin, E. (2009) Metabolic Syndrome and Risk Factors for Cardiovascular Disease: Are Nonagenarians Protected? Age (dordr), 31, 67-75. http://dx.doi.org/10.1007/s11357-008-9082-z

[23] Jesmin, S., Islam, R., Islam, S., Mia, S., Sultana, S.N. and Zaedi, S. (2012) Comprehensive Assessment of Metabolic Syndrome among Rural Bangladeshi Women. BioMed Central Public Health, 12, 49. http://dx.doi.org/10.1186/1471-2458-12-49

[24] Moebus, S., Hanisch, J.U., Aidelsburger, P., Bramlage, P., Wasem, J. and Jöckel, K.H. (2007) Impact of 4 Different Definitions Used for the Assessment of the Prevalence of the Metabolic Syndrome in Primary Healthcare: The German Metabolic and Cardiovascular Risk Projects (GEMCAS). Cardiovascular Diabetology, 6, 22. http://dx.doi.org/10.1186/1475-2840-6-22

[25] Mensah, G.A., Mokdad, A.H., Ford, E., Narayan, K.M., Giles, W.H., Vinicor, F. and Deedwania, P.C. (2004) Obesity, Metabolic Syndrome, and Type 2 Diabetes: Emerging Epidemics and Their Cardiovascular Implications. Cardiology Clinics, 22, 485-504. http://dx.doi.org/10.1016/j.ccl.2004.06.005

[26] Enas, E.A., Mohan, V., Deepa, M., Farooq, S., Pazhoor, S. and Chennikkara, H. (2007) The Metabolic Syndrome and Dyslipidemia among Asian Indians: A Population with High Rates of Diabetes and Premature Coronary Artery Disease. Journal of the Cardiometabolic Syndrome, 2, 267-275. http://dx.doi.org/10.1111/j.1559-4564.2007.07392.x

[27] Bengtsson, C., Lapidus, L., Stendahal, C. and Waldenstörm, J. (2002) Hyperuricemia and Risk of Cardiovascular Disease and Overall Death. A 12 Year Follow-Up of Participants in the Population Study of Women in Gothenburg, Sweden. Acta Medica Scandinavica, 224, 549-555.

[28] Cai, Z., Xu, X., Wu, X., Zhou, C. and Li, D. (2009) Hyperuricemia and the Metabolic Syndrome. Asia Pacific Journal Clinic Nutrition, 18, 81-87.

[29] Invitti, C., Maffeis, C., Giradini, L., Pontiggia, B., Mazzili, G., Girola, A., et al. (2006) Metabolic Syndrome in Obese Caucasian Children: Prevalence Using WHO-Derived Criteria and Association with Nontraditional Cardiovascular Risk Factors. International Journal of Obesity, 30, 627-633. http://dx.doi.org/10.1038/sj.ijo.0803151

[30] Ridker, P.M., Buring, J.E. and Cook, N.R. (2003) C-Reactive Protein, the Metabolic Syndrome, and Risk of Incident 
Cardiovascular Events: An 8-Year Follow-Up of 14719 Initially Healthy American Women. Circulation, 107, 391397. http://dx.doi.org/10.1161/01.CIR.0000055014.62083.05

[31] Langenberg, C., Bergstrom, J., Scheidt-Nave, C., Pfeilschifter, J. and Barrett-Connor, E. (2006) Cardiovascular Death and the Metabolic Syndrome. Role of Adiposity-Signaling Hormones and Inflammatory Markers. Diabetes Care, 29, 1363-1369. http://dx.doi.org/10.2337/dc05-2385

[32] Wald, D.S., Law, M. and Morris, J.K. (2002) Homocysteine and Cardiovascular Disease: Evidence on Causality from a Meta Analysis. BMJ, 325, 1202-1206. http://dx.doi.org/10.1136/bmj.325.7374.1202

[33] Ampara, V., Pilar, C., Natalia, B., Rafael, P., Antonio, H.M. and Dolores, C. (2011) Homocysteine Levels and the Metabolic Syndrome in a Mediterranean Population: A Case Control Study. Clinical Hemorheology and Microcirculation, 47, 59-66.

[34] Waldius, G. and Jungner, I. (2006) The ApoB/Apoa1 Ratio: A Strong, New Risk Factor for Cardiovascular Disease and a Target for Lipid-Lowering Therapy-A Review of the Evidence. Journal of Internal Medicine, 259, 493-519. http://dx.doi.org/10.1111/j.1365-2796.2006.01643.x

[35] Sierra-Johnson, J., Romero-Corral, J.A., Somers, V.K., Lopez-Jimenez, F., Walldius, G., Hamsten, A., et al. (2007) ApoB/ApoA-1 Ratio: An Independent Predictor of Insulin Resistance in US Non-Diabetic Subjects. European Heart Journal, 28, 2637-2643. http://dx.doi.org/10.1093/eurheartj/ehm360

[36] Zhong, L., Li, Q., Jiang, Y., Cheng, D., Liu, Z., Wang, B., et al. (2010) The ApoB/ApoA1 Ratio Is Associated with Metabolic Syndrome and Its Components in a Chinese Population. Inflammation, 33, 353-358. http://dx.doi.org/10.1007/s10753-010-9193-4

[37] Bazzano, L.A., Reynolds, K., Holder, K.N. and He, J. (2006) Effect of Folic Acid Supplementation on Risk of Cardiovascular Diseases: A Meta-Analysis of Randomized Controlled Trials. Journal of the American Medical Association, 296, 2720-2726. http://dx.doi.org/10.1001/jama.296.22.2720

[38] Sun, D.L., Wang, J.H., Jiang, B., Li, L.S., Li, L.S., Wu, L., Wu, H.Y. and He, Y. (2012) Metabolic Syndrome vs Its Components for Prediction of Cardiovascular Mortality: A Cohort Study in Chinese Elderly Adults. Journal of Geriatric Cardiology, 9, 123-129 
Scientific Research Publishing (SCIRP) is one of the largest Open Access journal publishers. It is currently publishing more than 200 open access, online, peer-reviewed journals covering a wide range of academic disciplines. SCIRP serves the worldwide academic communities and contributes to the progress and application of science with its publication.

Other selected journals from SCIRP are listed as below. Submit your manuscript to us via either submit@scirp.org or Online Submission Portal.
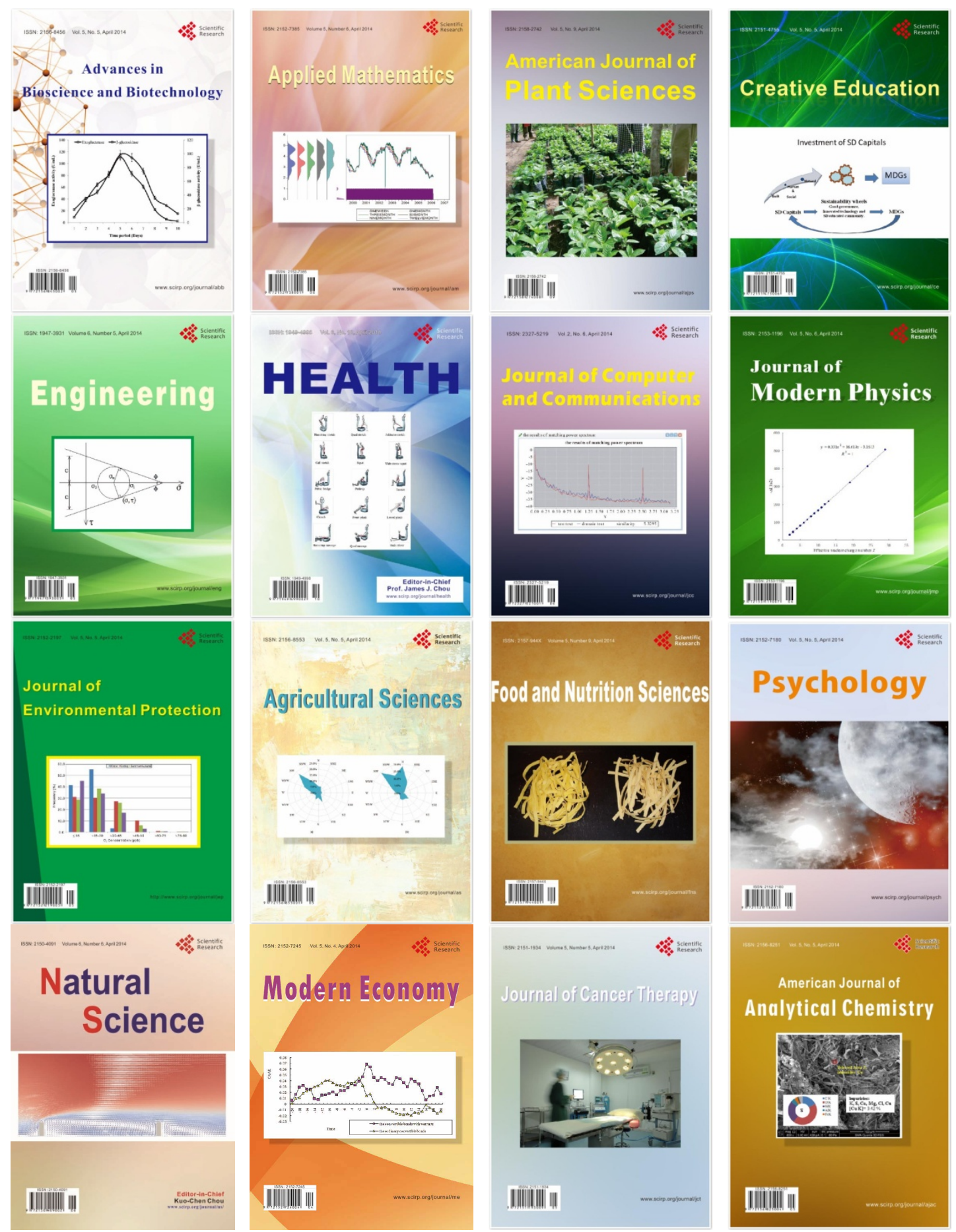